\title{
Apa yang Baru dalam Neuroanestesi untuk Cedera Otak Traumatik?
}

\author{
Dewi Yulianti Bisri*), Tatang Bisri**) \\ ${ }^{*}$ Departemen Anestesiologi dan Terapi Intensif Fakultas Kedokteran Universitas Padjadjaran-Bandung, \\ ${ }^{* *}$ Departemen Anestesiologi dan Terapi Intensif Fakultas Kedokteran Universitas Jenderal Achmad Yani-Cimahi
}

\begin{abstract}
Abstrak
Konsep dasar Neuroanestesi \& Neuro Critical Care disebut sebagai ABCDE neuroanestesi. Early Brain Injury (EBI) dahulu dikenal sebagai cedera otak primer. Pada EBI terjadi hilangnya autoregulasi, hilangnya integritas barier darah otak. Adanya Trias Cushing menunjukkan adanya hipertensi intrakranial. Target tekanan darah pada cedera otak traumatik (traumatic brain injury/TBI) adalah hindari tekanan darah sistolik <110 $\mathrm{mmHg}$, pertahankan tekanan perfusi otak (cerebral perfusion pressure/CPP) $60-70 \mathrm{mmHg}$, target pengaturan $\mathrm{PaCO}_{2}$ adalah normokarbia, $\mathrm{PaCO}_{2} 35-40 \mathrm{mmHg}$, penggunaan profilaksis phenytoin atau valproate tidak direkomendasikan untuk mencegah late post traumatic seizure (late PTS). Masih perlu menganalisa terapi decompressive craniectomy (DECRA) dibandingkan dengan terapi medikal kontinyu untuk peningkatan tekanan intrakranial (intracranial pressure/ICP) yang refrakter setelah TBI. Anestesi umum untuk pasien dengan TBI berat lebih baik dengan total intravenous anesthesia (TIVA), pemberian cairan harus mempertimbangkan osmolaritas cairan tersebut. Pada konsep yang baru, pada pasien dengan peningkatan ICP, konsentrasi anestetika volatil harus dibatasi sampai 0,5 MAC. Target gula darah adalah normoglikemia. Hipotermi profilaksis atau terapeutik tampaknya tidak memiliki tempat dalam pengelolaan cedera otak berat.
\end{abstract}

Kata kunci: cedera otak traumatik, neuroanestesi

JNI 2022 ; 11(1): 58-65

\section{What is New in Neuroanesthesia for Traumatic Brain Injury?}

\begin{abstract}
The basic concept of Neuroanesthesia and Neuro Critical Care is referred to as ABCDE neuroanesthesia. Early Brain Injury (EBI) was formerly know as primary brain injury. In EBI, there is loss of autoregulation, loss of integrity of the blood-brain barriere. The presence of Cushing's triad indicates the presence of intracranial hypertension. Blood pressure target in traumatic brain injury is to avoid systolic blood pressure less than 110 $\mathrm{mmHg}$, maintain cerebral perfusion pressure (CPP) 60-70 $\mathrm{mmHg}$, target $\mathrm{PaCO}_{2}$ regulation is normocarbia, $\mathrm{PaCO}_{2}$ $35-40 \mathrm{mmHg}$, prophylactic use of phenytoin or valproate is not recommended to prevent late post traumatic seizure (late PTS). Still need to analyse decompressive craniectomy (DECRA) compare with continuous medical therapy for refractory increase in intracranial pressure (ICP) after TBI. General anesthesia for patient with severe TBI is better with total intravenous anesthesia (TIVA), administration of fluids must consider the osmolarity of the fluid. In a new concept in patient with elevated ICP, volatile anesthetic concentaratiom should be limited to 0.5 MAC.Blood glucose target is normoglycemia. Prophylactic and therapeutic hypothermia not recommended for severe traumatic brain injury management.
\end{abstract}

Key words: neuroanesthesia, traumatic brain injury

JNI $2022 ; 11(1): 58-65$

This article is licensed under

Creative Commons Attribution-NonCommercial-ShareAlike 4.0 International License. 


\section{Pendahuluan}

Judul artikel ini merupakan kalimat tanya "What is New in Neuroanesthesia for Traumatic Brain Injury?" Pelaksanaaan penanganan pasien cedera otak traumatik berat berdasarkan panduan dari Brain Trauma Foundation Guideline edisi ke-4 tahun 2016. Akan tetapi, pada guideline 2016 itu tidak dibicarakan tentang bagaimana teknik dan obat neuroanestesi apabila pasien memerlukan tindakan pembedahan. Tulisan ini mengkaji pemikiran apa yang terjadi atau artikel apa yang ada dari periode setelah dipublikasikannya BTF Guideline 2016 sampai sekarang (periode 2016 - 2021), apakah ada yang berubah setelah 5 tahun berlalu terutama dalam kaitannya dengan neuroanestesi.

Konsep dasar Neuroanestesi \& Neuro Critical Care disebut sebagai ABCDE Neuroanestesi yaitu: A adalah Airway, clear airway artinya jalan nafas harus bebas sepanjang waktu, B adalah breathing dengan mengendalikan ventilasi untuk mencapai target normokapnia pada cedera otak traumatik (traumatic brain injury/TBI). C adalah circulation untuk menghindari peningkatan atau penurunan tekanan darah, hindari peningkatan tekanan vena serebral, normovolemia, isoosmoler. D singkatan dari drugs, artinya berikan obat yang mempunyai efek proteksi otak dan hindari obat yang dapat meningkatkan tekanan intrakranial (intracranial pressure/ICP). E adalah environment, pengendalian suhu tubuh dengan target $350 \mathrm{C}$ di kamar operasi dan $36^{\circ} \mathrm{C}$ di intensive care unit (ICU). Isi dari topik ini adalah mengkaji apakah ada yang berubah pada pengelolaan pasien TBI berat dari mulai dikeluarkannya BTF guideline 2016 sampai sekarang (tahun 2021). Airway, Breathing membicarakan pengaturan $\mathrm{PaCO}_{2}$, Circulation tentang pengaturan autoregulasi serebral/tekanan darah dan ICP, D-drug tentang obat anestesi dan Environment tentang pengaturan suhu tubuh pasien membahas tentang hipotermia terapeutik dan profilaktik. ${ }^{1,2}$

\section{Patofisiologi Early Brain Injury (EBI)}

Early Brain Injury dahulu dikenal sebagai cedera otak primer. Pada EBI terjadi hilangnya autoregulasi, hilangnya integritas barier darah otak. Konsep yang bersejarah dari EBI adalah adanya hipertensi sistemik yang sekunder terhadap adanya refleks Cushing. Adanya Trias Cushing menunjukkan adanya hipertensi intrakranial. Pada EBI terjadi pengeluaran masif dari katecholamine yang terlihat adanya perubahan EKG dan abnormalitas pergerakan dinding jantung. Terjadi pelepasan sitokin yang menyebabkan kebocoran kapiler dan edema paru. Konsep baru hipertensi setelah terjadi EBI adalah terjadinya pelepasan masif simpatis yang menyebabkan terjadinya hipertensi dan takikardia. Pelepasan sitokin dapat menyebabkan kebocoran kapiler sehingga terjadi edema paru.3 Bila tekanan darah menurun terjadi iskemia dan bila tekanan darah meningkat terjadi edema. Yang menjadi pertanyaan adalah berapa target tekanan darah pada TBI, berapa batas atas dan berapa batas bawah tekanan darah yang aman?

Jadi apa yang baru bila dibandingkan dengan BTF Guideline 2016? Yang berbeda adalah dalam hal definisi hipotensi. Definisi hipotensi untuk TBI pada BTF guideline 2007 adalah bila tekanan sistolik kurang dari $90 \mathrm{mmHg}$, sedangkan pada BTF guideline 2016 definisi hipotensi adalah bila tekanan sistolik kurang dari $110 \mathrm{mmHg}{ }^{4-6}$ Adakah perubahan pada periode 2017-2021? Berapa target tekanan arteri rata-rata (mean arterial pressure/MAP)?

\section{Pengaturan Tekanan Darah: Tekanan darah sistolik dan tekanan perfusi otak, Target tekanan darah pada pasien bedah saraf, batas atas dan batas bawahnya.}

\section{Konsep baru dinamika kurfe autoregulasi serebral}

Pada masa lalu, autoregulasi adalah MAP 50-150 $\mathrm{mmHg}$, yang mana pada rentang MAP 50-150 $\mathrm{mmHg}$, aliran darah otak (cerebral blood flow/ CBF) tetap dipertahankan antara 50-54 mL/100 gr jaringan/menit. Pada MAP dibawah $50 \mathrm{mmHg}$ walaupun dengan dilatasi maksimum, $\mathrm{CBF}$ akan menurun dan dapat terjadi iskemia serebral, infark serebral dan kematian sel neuron. Pada MAP diatas $150 \mathrm{mmHg}$ walaupun dengan konstriksi maksimum, CBF tidak dapat dipertahankan pada 
50-54 mL/100 gr jaringan/menit tapi meningkat dan dapat terjadi kerusakan blood-brain barriere dan terjadi edema otak..$^{2,6-10}$

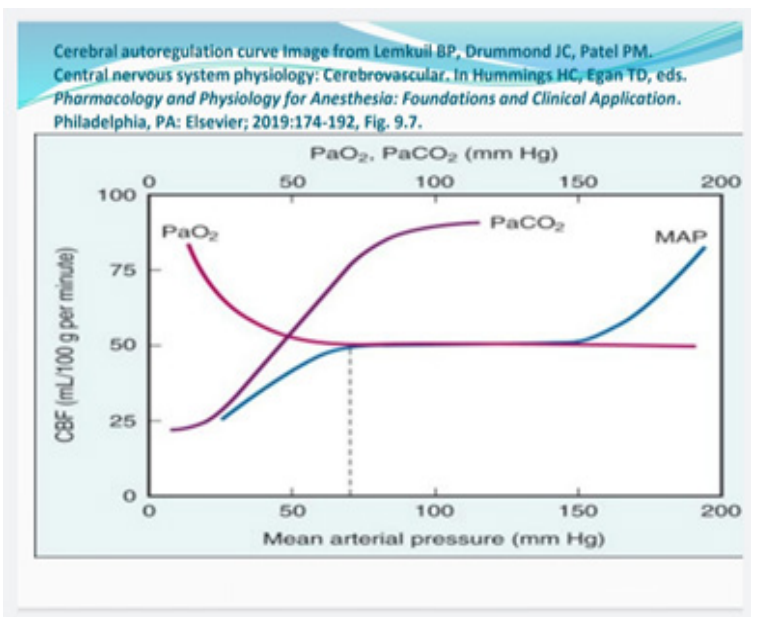

Gambar 1. Batas bawah autoregulasi menurut Miller Anesthesia 2020. 9

Untuk menjawab hal tersebut, rumus di bawah ini dapat dijadikan panduan:

$\mathrm{CPP}=\mathrm{MAP}-\mathrm{ICP}$
$\mathrm{MAP}=\mathrm{CPP}+\mathrm{ICP}$
$\mathrm{MAP}=60+(20$ atau 25$)=80-85$
$\mathrm{MAP}=70+(20$ atau 25$)=90-95$

Keterangan:

$\mathrm{CPP}=$ Cerebral Perfusion Pressure

MAP $=$ Mean Arterial Pressure

ICP = Intracranial Pressure

\section{Target Tekanan Perfusi Otak (Cerebral Perfusion Pressure/CPP)}

Menurut BTF 2007: target CPP 50-60 mmHg. ${ }^{4}$

Menurut BTF 2016 : target CPP 60-70 mmHg. ${ }^{5}$

Pada Miller Anesthesia 2020, batas bawah autoregulasi adalah MAP $70 \mathrm{mmHg}{ }^{9,10}$ Pemantauan CPP perlu dilakukan karena pengelolaan cedera kepala berat dengan menggunakan panduan berdasarkan rekomendasi untuk pemantauan CPP dapat menurunkan mortalitas 2 minggu. Target nilai CPP yang direkomendasikan untuk outcome yang baik adalah antara $60-70 \mathrm{mmHg}$. Apakah 60 atau $70 \mathrm{mmHg}$ merupakan ambang CPP optimal minimum masih belum jelas dan bergantung pada status autoregulasi pasien. Hindari tindakan agresif untuk mempertahankan CPP $>70 \mathrm{mmHg}$ dengan cairan dan pressors disebabkan adanya risiko terjadi adult respiratory failure, hindari $\mathrm{CPP}<50 \mathrm{mmHg}$ karena berisiko terjadinya iskemia serebral. ${ }^{2,5}$ Kenapa pada TBI rentang MAP nya begitu sempit? Hal ini disebabkan karena hilangnya autoregulasi serebral, hilangnya barier darah otak sehingga aliran darah otak bergantung pada MAP dan hipotensi akan menyebabkan hipoperfusi, sedangkan hipertensi menyebabkan hiperperfusi dan edema otak. Berdasarkan BTF Guideline 2016, rekomendasi ambang tekanan darah adalah mempertahankan tekanan darah sistolik $\geq 100 \mathrm{mmHg}$ untuk pasien yang berumur 50 sampai 69 tahun atau $\geq 110 \mathrm{mmHg}$ untuk pasien yang berusia 15 sampai 49 tahun atau $>70$ tahun, dipertimbangkan dapat menurunkan mortalitas dan memperbaiki outcome. Jadi apa yang baru? Yang baru adalah CPP dipertahankan $60-70 \mathrm{mmHg}$, dan hindari tekanan darah sistolik $<110$ mmHg. ${ }^{5}$

\section{Pengaturan $\mathrm{PaCO}$, pada TBI: Mengapa Penilaian $\mathrm{PaCO}_{2}$ perlu sesering mungkin?}

Aliran darah otak (cerebral blood flow/CBF) diatur terutama oleh autoregulasi, $\mathrm{PaCO} 2$ dan $\mathrm{PaO}_{2}$. Normal $\mathrm{CBF}$ adalah 50-54 mL/100 gr jaringan/menit dan setiap perubahan $1 \mathrm{mmHg}$ $\mathrm{PaCO}_{2} \mathrm{CBF}$ berubah 4\%. Pada BTF Guideline 2016 disebutkan bahwa sampai 4 jam setelah cedera otak traumatik berat, $\mathrm{CBF}$ menurun $50 \%$ dari nilai normal dan mencapai $80 \%$ nilai normal pada akhir 24-72 jam, oleh karena itu, hiperventilasi adalah kontraindikasi untuk 24 jam pertama setelah TBI. Pada Miller Anesthesia 2020 disebutkan bahwa targetnya adalah normocarbia, $\mathrm{PaCO}_{2}$ 35-40 mmHg, hipercarbia akan meningkatkan CBF dan menghilangkan kurfe autoregulasi sedangkan hipocarbia memelihara kurfe autoregulasi dengan menurunkan $\mathrm{CBF}^{5,9}$

\section{Rekomendasi Pemantauan Tekanan Intrakranial (Intracranial Pressure/ICP)}

Pengelolaan TBI berat menggunakan informasi dari pemantauan ICP direkomendasikan untuk mengurangi lama perawatan di rumahsakit dan 
mengurangi mortalitas 2 minggu setelah cedera. ICP harus dipantau pada semua salvageable pasien dengan TBI (Glasgow Coma Scale/GCS 3-8 setelah resusitasi) dan abnormal computed tomography (CT)-scan. Suatu CT-scan kepala yang abnormal adalah adanya hematoma, contusio, pembengkakan, herniasi, atau kompresi cisterna basalis. Indikasi pemantauaan ICP adalah pasien dengan TBI berat dengan CT-scan normal bila terdapat $\geq 2$ gambaran dibawah ini pada saat masuk ke rumahsakit: umur $>40$ tahun, unilateral atau bilateral motor posturing, atau tekanan darah sistolik $<90$ mmHg. ${ }^{4,5}$ Pada BTF 2007 guideline, rekomendasi ambang ICP untuk mulai dilakukan terapi kenaikan ICP bila ICP $>20 \mathrm{mmHg} .{ }^{4}$ Akan tetapi, pada BTF guideline 2016 terapi bila ICP $>22 \mathrm{mmHg}$ karena di atas level ini dihubungkan dengan meningkatnya mortalitas. Kombinasi nilai ICP, penemuan klinis dan CT-scan otak digunakan untuk keputusan penanganan pasien..$^{9,10}$

\section{Managemen Anestesi: Total Intravenous Anesthesia (TIVA) vs anestetika volatil: mana yang lebih baik?}

\section{Induksi anestesia}

Lakukan preoksigenasi, monitor tekanan darah setiap 1-2 menit, untuk induksi berikan anestetika intravena propofol atau pentotal atau etomidat, analgetik fentanyl atau remifentanyl, pelumpuh otot rocuronium dan lakukan gentle hiperventilasi, quick gentle intubasi. Target saat induksi, jangan sampai tekanan darah turun dibawah $110 \mathrm{mmHg}$, target CPP 60-70 mmHg, MAP 85-85 mmHg. ${ }^{3,7}$

\section{Rumatan anestesi}

Gunakan total intravenous anesthesia (TIVA) dengan propofol/remifentanyl/fentanyl infus. TIVA murni atau digabung dengan konsentrasi rendah volatil anestetika merupakan teknik anestesi yang populer dalam neuroanestesi, hindari volatil anestetik sampai dura dibuka. Pertahankan CPP 60-70 mmHg, kelola ventilasi berdasarkan nilai end tidal $\mathrm{CO}_{2}$. Berikan mannitol $1 \mathrm{gm} / \mathrm{kg}$ dalam waktu $15-20$ menit. ${ }^{2,7,9,10}$ Mengapa TIVA lebih disukai dalam neuroanestesi? Propofol mempertahankan kurfe autoregulasi serebral dan menurunkan ICP, anestetika volatil menekan autoregulasi serebral, konsentrasi anestetika volatile yang lebih dari $1 \mathrm{MAC}$ harus dihindari. Volatil anestetik mana yang harus digunakan? Harus paham tentang efek vasodilatasi serebral yang mana desfluran $>$ isoflurane $>$ sevoflurane. ${ }^{9,10}$ Bagaimana cara menurunkan ICP dengan cepat bila setelah dura dibuka, otaknya bengkak? Hentikan pemberian anestetika volatil, berikan bolus propofol dengan phenylepinephrine, mulai TIVA sebagai anestetika utama, lakukan hiperventilasi sampai masalahnya hilang dan kemudian pertahankan normokarbia., ${ }^{3,7}$ Pada konsep yang baru, pada pasien dengan peningkatan ICP, konsentrasi anestetika volatil harus dibatasi sampai 0,5 MAC. Pada penambahan volume intrakranial seperti pada TBI, anestetika volatil harus dihindari setidaknya sampai dura dibuka. ${ }^{9,10}$

\section{Profilaksis Anti Kejang}

\section{Seizure Prophylaxis}

Keluhan seizure akut dapat terjadi sebagai akibat dari cedera otak traumatik (TBI) berat. Posttraumatic seizure (PTS) diklasifikasikan sebagai early bila terjadi dalam 7 hari setelah cedera atau late bila terjadi setelah 7 hari cedera. Posttraumatic epilepsy (PTE) didefinisikan sebagai seizure rekuren lebih dari 7 hari setelah cedera. Pada pasien dengan TBI berat, laju clinical PTS kira-kira $12 \%$, sedangkan seizure subklinis yang dideteksi dengan elektroencefalografi sekitar 20-25\%. Faktor risiko untuk early PTS adalah skor Glasgow Coma Scale (GCS) $\leq 10$, immediate seizures, post-traumatic amnesia yang berakhir lebih dari 30 menit, skull fraktur linear atau depres, cedera kepala penetrasi, hematoma subdural, epidural, atau intraserebral, kontusio kortikal, umur $\leq 65$ tahun, alkoholisme kronik. ${ }^{4,5}$ Satu penelitian pada tahun 2010 menunjukkan bahwa laju PTE lebih tinggi daripada risiko berkembangnya epilepsi secara umum. Risiko untuk PTE adalah individu yang mengalami TBI berat, early PTS, acute intracerebral hematoma atau cortical contusion, posttraumatic amnesia yang berakhir lebih dari 24 jam, umur $>65$ tahun, atau ada riwayat depresi premorbid. ${ }^{5}$

Profilaksis seizure untuk PTS mengacu pada praktek pemberian antikonvulsan pada pasien TBI dalam target mencegah terjadinya seizure. 
Rasionalisasi untuk pemberian profilaksis seizure secara rutin adalah karena kejadian seizure pada pasien TBI berat relatif tinggi dan ada kemungkinan keuntungan untuk mencegah setelah TBI (misalnya membatasi kekacauan fisiologi akut, mencegah terjadinya epilepsi kronis, mencegah herniasi dan kematian). Akan tetapi, itu juga diinginkan untuk mencegah neurobehavioral dan efek samping lain dari obat ini, terutama bila tidak efektif dalam mencegah seizure. Karena itu, penting untuk mengevaluasi keuntungan secara menyeluruh, juga bahayanya dari obat antikonvulsan yang digunakan untuk mencegah PTS. 3,5

Penggunaan levetiracetam meningkat untuk profilaksis seizure dari berbagai patologi, termasuk juga TBI. Tersedianya penelitian komparatif, kurang memadai untuk mendukung pemberian rekomendasi atau melarang penggunaan levetiracetam, diperlukan penelitian selanjutnya untuk memahami kemungkinan keuntungan atau bahaya dari levetiracetam dalam terapi pasien TBI. ${ }^{5}$ Penggunaan profilaksis phenytoin atau valproate tidak direkomendasikan untuk mencegah late PTS. Phenytoin telah direkomendasikan untuk menurunkan kejadian early PTS (dalam 7 hari cedera), dimana keuntungan keseluruhan terasa melebihi komplikasi yang terkait dengan terapi ini. Akan tetapi, early PTS tidak dihubungkan dengan lebih buruknya outcome. Pada saat ini tidak cukup bukti untuk merekomendasikan levetiracetam lebih baik dari phenytoin dalam hal keuntungan pencegahan early post-traumatic seizures dan toksisitas. Dosis phenitoin pada dewasa; 10-15 $\mathrm{mg} / \mathrm{kg}$ berat badan, diberikan dengan suntikan lambat atau infus dengan kecepatan tidak lebih dari $50 \mathrm{mg} / \mathrm{menit}$. Dosis pemeliharaan $100 \mathrm{mg}$ yang diberikan tiap 6-8 jam sekali (bisa juga per oral). Dosis letal pada dewasa $2-5$ gram/ hari. Dosis phenitoin untuk anak; 15-20 mg/ $\mathrm{kg}$ BB dengan kecepatan tidak melebihi 1-3 $\mathrm{mg} / \mathrm{kg}$ per menit. ${ }^{5}$ Penelitian meta-analysis dan systematic review yang dipublikasikan pada tahum 2019 tentang anti-seizure prophylaxis padaTBI yang terdiri dari 3 RCTs $(n=750)$ dan 6 penelitian observasional $(n=3362)$ menunjukkan hasil bahwa keuntungannya terbatas hanya pada pencegahan early seizure. ${ }^{11}$

\section{Decompressive Craniectomy (DC)}

Decompressive craniectomy bifrontal tidak direkomendasikan untuk memperbaiki outcome yang dinilai dengan skor Extended Glasgow Outcome Scale (GOSE) pada 6 bulan setelah cedera pada pasien cedera otak traumatik berat dengan cedera difus (tanpa lesi massa), dan dengan peningkatan ICP $>20 \mathrm{mmHg}$ lebih dari 15 menit dalam periode 1 jam yang refrakter terhadap first-tier therapy. Akan tetapi, prosedur DC ini telah ditunjukkan untuk mengurangi ICP dan mengurangi lama perawatan di ICU. Suatu frontotemporoparietal DC yang besar (tidak kurang dari $12 \times 15 \mathrm{~cm}$ atau 15 $\mathrm{cm}$ diameter) direkomendasikan daripada DC frontotemporoparietal yang kecil untuk menurunkan mortalitas dan memperbaiki outcome neurologis pada pasien dengan TBI berat. ${ }^{2,5,13}$ Penelitian Randomized Evaluation of Surgery with Craniectomy for Uncontrollable Elevation of Intracranial Pressure (RESCUEicp), dilakukan pada 408 pasien dengan peningkatan ICP yang refrakter $(>25 \mathrm{mmHg})$. Penelitian tersebut membandingkan terapi DECRA dengan terapi medikal kontinyu untuk peningkatan ICP yang refrakter setelah TBI. Penilaian pada 6 bulan DC menunjukkan lebih rendahnya mortalitas tapi lebih tingginya vegetative state, lower severe disability dan upper severe disability daripada terapi medikal. Sedangkan moderate disability dan good recovery sama antara kedua kelompok. ${ }^{13}$

\section{Pengelolaan Cairan pada TBI}

Osmolalitas normal salin mendekati plasma sedangkan ringer laktat sedikit hipotonik. Cairan yang kaya klorida dapat berkontribusi terjadinya hiperkloremik asidosis dan mengganggu aliran darah renal, maka ringer laktat umum digunakan pada operasi bedah saraf. Akan tetapi, osmolaritas RL $273 \mathrm{mOsm} / \mathrm{L}$ dan $\mathrm{NaCl}$ adalah $304 \mathrm{mOsm} / \mathrm{L}$ sedangkan plasma $290 \mathrm{mOsm} / \mathrm{L}$, balans solution ringerfundin mempunyai osmolaritas $309 \mathrm{mOsm} / \mathrm{L} .{ }^{2}$ Osmolaritas cairan $>290 \mathrm{mOsm} / \mathrm{L}$ disebut hiperosmoler, sedangkan $<290 \mathrm{mOsm} / \mathrm{L}$ disebut hipoosmoler, dengan 
demikian perlu digunakan cairan yang melebihi osmolaritas plasma. ${ }^{2}$ Penggantian cairan saat operasi bedah saraf adalah $50 \%$ dari jumlah urine bila diberikan mannitol, sasarannya adalah euvolemia. Bila diperlukan cairan dalam jumlah banyak (lebih dari 2 liter) dapat diberikan $\mathrm{NaCl}$ atau $\mathrm{RL}$ atau ringerfundin. Tidak perlu dilakukan penghangatan cairan, cukup dengan suhu kamar operasi. ${ }^{3}$ The Saline versus Albumin Fluid Evaluation (SAFE) trial pada pasien dengan TBI berat (GCS3-4), menunjukkan bahwa pemberian albumin 4\% menunjukkan mortalitas 30 hari yang lebih tinggi daripada yang diberikan $\mathrm{NaCl}^{14}$ Akan tetapi, ada keterbatasan pada SAFE trial ini yaitu tidak dilakukan randomisasi pasien TBI, albumin $4 \%$ bersifat hipoosmoler (osmolaritasnya $274 \mathrm{mOsm} / \mathrm{L}$ ). Sebaliknya penelitian di Swedia, yang merupakan penelitian retrospektif $(n=93)$, menunjukkan lebih rendahnya mortalitas 28 hari dan 18 bulan pada TBI berat bila digunakan albumin dengan balans cairan nol atau negatip.

Bagaimana dengan terapi hiperosmolar? Mannitol dengan salin hipertonik mana yang lebih baik? Hypertonic salin (HTS) menurunkan ICP lebih baik daripada mannitol tanpa perbedaan outcome dalam jangka waktu singkat. Pada BTF guideline 2007 disebutkan bahwa HTS lebih disukai daripada mannitol pada pasien TBI. Pada BTF guideline 2016, baik mannitol atau HTS, keduanya dapat diterima. Suatu penelitian metaanalisis pada tahun 2019 (12 $\mathrm{RCT}, \mathrm{n}=464$ ) menunjukkan penurunan ICP lebih baik dengan HTS pada interval 30-120 menit, tapi tidak ada perbedaan outcome saat keluar dari rumahsakit. Sayangnya pada metaanalisis ini tidak ada penelitian outcome jangka panjang. Review Cochrane pada tahun 2020 ( $\mathrm{n}=287,6$ RCT) membandingkan mannitol vs HTS, 91\% pasiennya mempunyai GCS kurang dari 8 (TBI berat), dan kesimpulannya adalah tidak ada perbedaan dalam outcome. ${ }^{4,5}$

\section{Manajemen Glukosa}

Hiperglikemia sering terjadi pada fase awal setelah TBI dan berhubungan dengan outcome yang buruk. Sementara hiperglikemia akut bersifat toksik, tapi besarnya peningkatan glukosa darah yang diperlukan untuk menyebabkan kerusakan tetap, tidak pasti. Patogenesis stres hiperglikemia secara luas dianggap mewakili interaksi kompleks antara katekolamin endogen, sitokin dan aktivasi aksis hipotalamus-hipofisis-adrenal yang mengakibatkan sekresi kortisol yang berlebihan dan memicu glukoneogenesis. Hal ini semakin diperburuk oleh intervensi terapeutik seperti pemberian katekolamin dan steroid eksogen, dan resistensi insulin yang mendasari atau gangguan sekresi insulin. Mekanisme patofisiologi dimana hiperglikemia dapat memperburuk outcome TBI diduga termasuk promosi jalur stres oksidatif dan induksi neuroinflamasi. ${ }^{15,16}$

Penatalaksanaan hiperglikemia pada TBI saat ini melibatkan penggunaan short-acting insulin yang diberikan sebagai infus intravena kontinu, dititrasi untuk mempertahankan glukosa darah sistemik dalam rentang target yang telah didapat dari uji coba terkontrol secara acak di unit perawatan intensif medis atau bedah umum (ICU). Studi Van den Berghe et al., mengakibatkan perubahan paradigma dalam pendekatan manajemen glukosa darah pada pasien kritis, berdasarkan temuan mereka bahwa menargetkan kontrol glikemik intensif (4,4-6,1 $\mathrm{mmol} / \mathrm{L}$ ) mengurangi kematian pada populasi ICU bedah, meskipun ada peningkatan kejadian hipoglikemia. Sementara ada penggunaan yang cukup besar dari cara ini, penelitian RCT multicenter berikutnya mengkonfirmasi adanya insiden yang lebih tinggi dari hipoglikemia berat dengan cara kontrol glikemik intensif dan membantah pengamatan awal dengan mengidentifikasi peningkatan mortalitas dengan terapi intensif kontrol glukosa darah. ${ }^{15,16}$ Kontrol glikemik intensif tidak mengurangi mortalitas pada pasien dengan TBI tetapi sangat meningkatkan risiko hipoglikemia. Sinyal menuju peningkatan hasil neurologis dengan kontrol glikemik intensif pada pasien pasca TBI memerlukan penyelidikan. Ini mungkin paling baik dilakukan dengan menggunakan pendekatan yang lebih aman untuk kontrol glikemik yang mengurangi risiko hipoglikemia, menggunakan target gula darah bertingkat yang memperhitungkan heterogenitas fisiologis pada pasien dengan TBI. ${ }^{15,16}$ 


\section{Hipotermia}

Deliberate hypothermia (hipotermia profilaksis) dalam pengelolaan awal TBI tidak meningkatkan outcome neurologis pada 6 bulan. Induksi hipotermia juga dapat meningkatkan risiko pneumonia. Hipotermia $\left(33-35^{\circ} \mathrm{C}\right)$ kadangkadang diinduksi untuk mencoba dan membatasi kerusakan otak pada orang dengan cedera kepala berat. Namun bukti untuk keamanan dan keefektipannya telah beragam. Sebuah penelitian pada tahun 2015 (Eurotherm 3235) menemukan bahwa terapeutik hipotermia, untuk dewasa dengan peningkatan tekanan intrakranial, tidak menghasilkan outcome yang lebih baik daripada terapi standar yang tidak melakukan terapeutik hipotermia. ${ }^{17,18}$ Percobaan The Prophylactic Hypothermia Trial to Lessen Traumatic Brain Injury-Randomized Clinical Trial (POLAR-RCT) ini lebih besar, dan hipotermi diinduksi sesegera mungkin setelah cedera otak, terlepas dari tandatanda pembengkakan otak. Secara keseluruhan, uji coba ini tidak mendukung praktik hipotermia profilaksis atau terapeutik setelah cedera kepala. ${ }^{17,18}$ Mengapa studi ini diperlukan? Pada tahun 2016/2017 hampir 156.000 orang dirawat di rumah sakit Inggris setelah cedera kepala. Kirakira $1 / 5$ akan memiliki fitur yang menunjukkan patah tulang tengkorak atau memiliki bukti kerusakan otak. Efek jangka panjang dari TBI dapat sangat bervariasi dalam tingkat keparahan, tetapi termasuk kesulitan kognitif (berpikir), fungsional (aktivitas), perilaku dan emosional.

Pembengkakan atau perdarahan di dalam atau sekitar otak akibat TBI dapat meningkatkan tekanan didalam tengkorak, menyebabkan kerusakan pada otak atau membatasi pasokan darah. Hipotermia bisa efektip dalam mengurangi tekanan intrakranial, tetapi tidak jelas apakah ini meningkatkan kelangsungan hidup atau fungsi otak. ${ }^{17,18}$ Hipotermia profilaksis tidak membuat perbedaan untuk hasil neurologis yang menguntungkan pada 6 bulan. Pada 6 bulan, tidak ada perbedaan kematian antara kelompok hipotermia dan kelompok perawatan biasa $(21,1 \%$ vs $18,4 \%)$. Juga tidak ada perbedaan waktu kematian. Pada 10 hari, ada sedikit lebih banyak efek samping pada kelompok hipotermia, tapi tidak signifikan. Pneumonia 55,0\% pada hipotermia dan $51,3 \%$ pada perawatan biasa. 5,17,18 Pedoman National Institute for Health and Care Excelence (NICE) pada tahun 2017 tentang pengelolaan cedera kepala, tidak menyebutkan penggunaan hipotermia terapeutik. Hasil yang dikumpulkan dari 6 uji coba terkontrol acak kualitas sedang menunjukkan bahwa hipotermia dapat meningkatkan hasil neurologis, tapi tidak ada penurunan mortalitas yang konsisten atau signifikan secara statistik. Sebagai simpulan hipotermi profilaksis atau terapeutik tampaknya tidak memiliki tempat dalam pengelolaan cedera otak berat., ${ }^{5,17,18}$ Hipotermia Profilaksis: Early (dalam 2,5 jam), short-term (48 jam setelah cedera), hipotermia profilaksis tidak dianjurkan untuk memperbaiki outcome pada pasien dengan cedera difus. ${ }^{5}$

\section{Simpulan}

Simpulan yang dapat diambil dari tulisan ini adalah: tidak banyak perubahan dari Brain Trauma Foundation Guideline 2016 sampai sekarang. Pertahankan CPP 60-70 mmHg, dan hindari tekanan darah sistolik $<110 \mathrm{mmHg}$. Target pengaturan $\mathrm{PaCO}_{2}$ adalah normocarbia, $\mathrm{PaCO}_{2} \quad 35-40$ mmHg, hipercarbia akan meningkatkan $\mathrm{CBF}$ dan menghilangkan kurfe autoregulasi sedangkan hipocarbia memelihara kurfe autoregulasi dengan menurunkan CBF. Penggunaan profilaksis phenytoin atau valproate tidak direkomendasikan untuk mencegah late PTS. Masih perlu menganalisa terapi DECRA dengan terapi medikal kontinyu untuk peningkatan ICP yang refrakter setelah TBI. Target gula darah adalah normoglikemia. Hipotermi profilaksis atau terapeutik tampaknya tidak memiliki tempat dalam pengelolaan cedera otak berat. Anestesi umum untuk pasien dengan TBI berat, lebih baik dengan total intravenous anesthesia (TIVA). Pemberian cairan harus mempertimbangkan osmolaritas cairan tersebut dan tidak ada perbedaan outcome pemberian mannitol dengan HTS.

\section{Daftar Pustaka}

1. Bisri DY, Bisri T. Dasar-dasar Neuroanestesi. 
Bandung: Fakultas Kedokteran Universitas Padjadjaran; 2019

2. Bisri DY, Bisri T. Pengelolaan Perioperatif Cedera Otak Traumatik. Bandung: Fakultas Kedokteran Universitas Padjadjaran;2018

3. D'Souza S. Neuroanesthesia update 2020

4. Bratton S, Bullock MR, Carney N, Chesnut RM, Coplin W, Ghajar J. Guidelines for the Management of Severe Traumatic Brain Injury 3th Edition. Journal of Neurotrauma 2007;24, Supp 1.

5. Carney N, Totten AM, O'Reilly C, Ullman JS, Hawryluk GWJ, Bell MJ. Guidelines for the Management of Severe Traumatic Brain Injury 4th Edition, September 2016

6. Geeraerts T, Velly L, Abdennour L, Asehnoune K, Audibert G, Bouzat P, et al. Management of severe traumatic brain injury (first 24 hours). Anaesth Crit Care Pain Med 2018;37: 171-86

7. Pasternak JJ, Lanier WL. Neuroanesthesiology update. J Neurosurg Anesthesiol 2017;29(2):97-131

8. D'souza S. Blood pressure target in neurosurgical patients: how high and how low should we go? Journal of Alzheimer \& Dementia 2019;2(2): 2019

9. Patel PM, Drummond JC, Lemkuil PB. Cerebral physiologyand the effectofanesthetic drug. In: Gropper MA, Cohen NH, Eriksson LI, Fleiser LA, Leslie K, Weiner-Kronish JP, eds. Miller's Anesthesia, 9th ed 2020

10. Lemkuil PB, Drummond JC, Patel PM, Lam A. Anesthesia for neurologic surgery and neurointerventions. In: Gropper MA, Cohen NH, Eriksson LI, FleiserLA, Leslie K, WeinerKronish JP, eds. Miller's Anesthesia, 9th ed, Philadelphia: Elsevier 2020,1868-1910

11. Hawryluk GW, Aguilera S, Buki A, Bulger
E, Citero G, Cooper DJ, et al. A management algorithm for patients with intracranial pressure monitoring: the Seattle International Severe Traumatic Brain Injury Consensus Conference (SIBICC). Intensive Care Med 2019;45(12):1783-94

12. Gormley WB, Arnaout O, Aglio LS, Smith T, Zaidi H. The effectiveness of antiepileptic medications as prophylaxis of early seizure in patient with traumatic brain injury compared with placebo or no treatment: a systematic review and meta-analysis. World Neurosurg 2019;122:433-40

13. Hutchinson PJ, Kolias AG, Timofeev IS, Corteen EA, Czosnyka M, Timothy J, et al. Trial of decompressive craniectomy for traumatic intracranial hypertension. N Engl J Med 2016;375:1119-30

14. Myburgh J, Cooper JD, Finfer S. Saline or albumin for fluid resuscitation in patient with traumatic brain injury. N Engl J Med 2007;357:874-84

15. Hermanides J, Plummer MP, Finnis M, Deane AM,Coles JP, Menon DK. Glycaemic control targets after traumatic brain injury: a systematic review and metaanalysis. Critical Care 2018;22:11

16. Godoy DA, Behrouz R, Napoli MD. Glucose control in acute brain injury: does it matter? Curr Opin Crit Care 2016 Apr;22(2):120-7

17. Andrew PJD, Sinclair HL, Rodriguez A, Harris BA, Battison CG, Rhodes JKJ, et al. Hypothermia for intracranial hyperension after traumatic brain injury. N Engl J Med 2015;373:2403-12

18. Cooper DJ, Nichol AD, Bailey M, Bernard S, Cameron PA, Pili-Floury S, et al. Effect of early sustained prophylactic hypothermia on neurologic outcome among patient with severe traumatic brain injury: The POLAR randomized clinical rial. JAMA 2018;320(21):2211-20 